\title{
Surgical Management of Pituitary Adenomas
}

J A Jane, Jr., E R Laws, Jr.

\section{ABSTRACT}

Pituitary adenomas are a diverse group of benign neoplasms. The hormonally active tumours present with well-recognised syndromes and include acromegaly (growth hormone adenoma), Cushing's disease (corticotropin adenoma), and amenorrhea-galactorrhea (prolactin adenoma or prolactinomas). The hormonally inactive, or clinically non-secreting, adenomas generally come to clinical attention secondary to local mass effect or pituitary deficiency. With the exception of the prolactinomas, transsphenoidal surgery remains the first-line therapy for most pituitary adenomas. The current diagnosis and surgical management of pituitary adenomas is discussed.

Keywords: pituitary neoplasm, Cushing syndrome, Acromegaly, Prolactinoma, transsphenoidal surgery

Singapore Med J 2002 Vol 43(6):3 I 8-323

\section{INTRODUCTION}

Pituitary adenomas are broadly classified according to either their size or functional status (Table I). Adenomas measuring $\leq 10 \mathrm{~mm}$ are considered microadenomas; those larger than $10 \mathrm{~mm}$ are termed macroadenomas. The other classification scheme distinguishes whether the tumours are associated with clinical and laboratory evidence of excess hormone secretion. The traditional nomenclature describes adenomas as hyperfunctioning or nonfunctioning. The three most common hyperfunctioning adenomas are the prolactin (PRL) secreting adenoma, the growth hormone $(\mathrm{GH})$ adenoma, and the corticotropin (ACTH) adenoma. Much less common is the hypersecreting thyroid stimulating hormone (TSH) adenoma. The non-functioning adenomas (NFA) actually represent a group of adenomas that include the glycoprotein adenomas [ $\alpha$-subunit, thyrotropin (TSH), follicle stimulating hormone (FSH), and luteinising hormone $(\mathrm{LH})]$, the null cell adenoma and oncocytoma.

Although prolactinomas have accounted for nearly $30 \%$ of the cases in our surgical series since 1972, the surgical indications have narrowed and its frequency with regard to surgical management has diminished (Table II). Growth hormone adenomas and $\mathrm{ACTH}$ adenomas account for approximately $20 \%$ and $15 \%$, respectively, of the tumours treated surgically in our series ${ }^{(1)}$. Clinically non-functioning adenomas account for approximately $35 \%$ of our cases.

\section{CLINICAL PRESENTATION}

Pituitary adenomas present to the clinician secondary to production of excess hormone, secondary to mass effect, or incidentally. Although not mutually exclusive, the presentations will be discussed individually.

Table I. Classification Schemes of Pituitary Adenomas.

Department of

Neurosurgery

University of Virginia

Health Sciences Center, PO Box 800212

Charlottesville,

Virginia 22908

J A Jane, Jr., MD

Chief Resident

E R Laws, Jr., MD Professor

Correspondence to: Prof E R Laws, Jr.

Tel: (434) 9242650

Fax: (434) 9245894

Email: el5g@

virginia.edu
Features

\begin{tabular}{ll} 
Scheme & Features \\
\hline $\begin{array}{l}\text { Size } \\
\text { Microadenoma }\end{array}$ & $\leq 10$ millimeters \\
Macroadenoma & $>10$ millimeters \\
\hline $\begin{array}{l}\text { Functional status } \\
\text { Non-functioning adenoma }\end{array}$ & Although clinically no evidence of excess secretion, the patient may present with pituitary \\
& deficiency or mild hyperprolactinemia secondary to "stalk effect". \\
Hyperfunctioning adenoma & Excess of hormonally active pituitary hormone \\
& GH adenoma (Acromegaly) \\
& PRL adenoma (Amenorrhea-Galactorrhea) \\
& ACTH adenoma (Cushing's Disease, Nelson's syndrome) \\
TSH adenoma & Mixed GH and PRL adenoma \\
& Other plurihormonal adenomas
\end{tabular}




\section{Hypersecretory Syndromes}

Prolactin secreting adenomas present most commonly in women with amenorrhoea and galactorrhoea. Although men can present with galactorrhoea, they more often come to attention secondary to visual symptoms or signs of pituitary deficiency. The impaired anterior pituitary function may manifest with diminished libido, fatigue, and loss of vitality. Caution must be used in the diagnosis of prolactinomas solely based on clinical grounds because neither amenorrhoea nor galactorrhea is specific to prolactinomas. Any tumor that impinges on the pituitary stalk, and thereby disrupts the tonic inhibition of prolactin secretion by the hypothalamus, may cause a rise in serum prolactin with secondary amenorrhoea and galactorrhoea.

Growth hormone adenomas cause either acromegaly in adults or gigantism if the disease onset is prior to the closure of the epiphyseal plates. Patients with acromegaly experience progressive, and often insidious, cosmetic changes. These changes include frontal bossing, prognathism, macroglossia, and an increase in hand and foot size. Patients also experience hypertension, congestive heart failure, and impaired glucose metabolism. Tissue hypertrophy also increases the incidence of sleep apnea, lumbar stenosis, and carpal tunnel syndrome. Growth hormone excess in adolescents causes the additional feature of excessive long bone growth and subsequent increased stature.

Excess ACTH production leads to hypercortisolemia and Cushing's syndrome. Cushing's syndrome is distinguished from Cushing's disease in that the latter is secondary to overproduction of ACTH by a pituitary adenoma. Like acromegaly, patients present with a constellation of characteristic cosmetic changes. These changes include weight gain with centripetal obesity, moon facies, and fat deposition in the supraclavicular and post-cervical regions (buffalo hump). Integumentary features include hyperpigmentation, abdominal purple striae, hirsutism, plethora, and easy bruisability. Excess cortisol also may cause hypokalemia, hypertension, osteoporosis, and diabetes mellitus. Other features include depression with labile affect, loss of libido, amenorrhoea, and proximal myopathy.

\section{Mass Effect}

In addition to these classical syndromes of hormonal excess, pituitary tumors also may produce signs and symptoms secondary to mass effect. Mass effect may manifest with either local pituitary dysfunction or extrasellar neurological signs.

Local growth within the sella can cause the gradual onset of pituitary dysfunction. The most susceptible cells are the gonadotrophs, followed by the thyrotrophs, somatotrophs, and corticotrophs.
Table II. Transsphenoidal surgery for Adenomas: case summary (1972-2000).

\begin{tabular}{lc}
\hline Type of Adenoma & $\begin{array}{c}\text { Number of Patients (\%) } \\
\mathrm{N}=3093\end{array}$ \\
\hline $\begin{array}{l}\text { Hyperfunctioning adenomas } \\
\text { GH adenoma (Acromegaly) }\end{array}$ & 537 (I7.4) \\
PRL adenoma & $889(28.7)$ \\
ACTH adenoma (Cushing's disease) & $490(15.8)$ \\
Post-adrenalectomy ACTH adenoma & $65 \quad(2.1)$ \\
(Nelson-Salassa syndrome) & \\
TSH adenoma & $39(1.3)$ \\
Non-functioning adenomas & $1073(34.7)$ \\
\hline
\end{tabular}

In women, gonadotroph ( $\mathrm{LH}$ and FSH) dysfunction causes amenorrhoea, decreased libido, and osteoporosis. In men, the resultant reduced testosterone often presents with impotence as well as decreased libido and vitality. Patients with secondary thyroid deficiency exhibit decreased vitality, cold intolerance, dry skin, and myalgias. Growth hormone deficiency may cause fatigue and reduced exercise performance but also carries the long-term risk of reduced cardiac performance. Corticotroph deficiency, when manifested gradually, presents with fatigue, anorexia, and depression. When corticotroph deficiency occurs acutely, as in the setting of pituitary apoplexy, cortisol deficiency (Addisonian crisis) may cause stupor, cardiovascular collapse, hyponatremia, and hyperkalemia.

Extension of an adenoma outside the confines of the sella may cause neurological signs. Suprasellar extension that impinges upon the optic chiasm leads to the characteristic bitemporal hemianopsia. Massive suprasellar growth with expansion into the third ventricle, albeit rare, can cause obstructive hydrocephalus. Growth into the cavernous sinus may provoke extraocular motion abnormalities, ptosis, and facial pain. With even more lateral expansion into the temporal lobes, giant adenomas can trigger seizures.

\section{Incidental adenomas}

With the increased availability of magnetic resonance imaging (MRI), more patients are presenting with incidentally diagnosed pituitary adenomas. Incidentally diagnosed adenomas, however, are not universally asymptomatic, nor can they all be managed conservatively. Although microadenomas pose a minimal risk of pathological growth, more than onethird of incidentally discovered macroadenomas will grow significantly over time ${ }^{(2-6)}$. Pituitary dysfunction is evident in up to $15 \%$ and these patients should be treated with hormonal replacement therapy ${ }^{(3)}$. 


\section{DIAGNOSIS}

The diagnosis of pituitary adenomas begins with a careful neurological and endocrinological history and examination. Although many centres offer a multidisciplinary clinical evaluation of pituitary disorders that include both neurosurgeons and endocrinologists, at other centres this is not available. For this reason, when a patient presents with a visual field deficit, the initial screening should begin with a serum prolactin level. Because the firstline treatment of prolactinomas is medical therapy, a serum prolactin level will determine to whom, endocrinologist or neurosurgeon, the patient should be referred.

\section{Endocrine Evaluation \\ Prolactinomas}

Prolactin secreting adenomas are among the more straightforward of pituitary tumors to diagnose. Serum prolactin levels $>200 \mathrm{ng} / \mathrm{ml}$ are generally considered secondary to a prolactin secreting adenoma. Nevertheless, moderate hyperprolactinemia (serum PRL $<150 \mathrm{ng} / \mathrm{ml}$ ) may occur in patients with pituitary lesions that impinge upon the pituitary stalk. Impingement upon the pituitary stalk interrupts hypothalamic inhibition of prolactin secretion and leads to disinhibition of pituitary lactotrophs.

\section{Acromegaly}

Because growth hormone secretion is normally pulsatile, random $\mathrm{GH}$ levels are of limited value in the diagnosis of acromegaly. IGF-1 levels more accurately reflect the overall $\mathrm{GH}$ levels and should be used to screen for a suspected GH adenoma. An oral glucose tolerance test (OGTT) can confirm the diagnosis. Serum growth hormone levels are drawn in the fasted patient at -30, 0, 30, 60, 90, and 120 minutes around the time of an oral glucose load of 75 to 100 grams. Failure to suppress GH levels to less than $1 \mu \mathrm{g} / \mathrm{L}$ $(<2 \mathrm{mU} / \mathrm{L})$ confirms the diagnosis.

\section{Cushing's Disease}

Cushing's disease is amongst the most difficult of endocrine disorders to accurately diagnose. The initial endocrinological step is to confirm Cushing's syndrome. A 24-hour urinary free cortisol (UFC) may be used to screen for Cushing's syndrome. Values above 220-330 nmol/24 hours (80-120 $\mu \mathrm{g} /$ 24 hours) are sensitive, but relatively non-specific, for the diagnosis of Cushing's syndrome ${ }^{(7,8)}$. The overnight low-dose dexamethasone suppression test (LDDST) may also be used for screening and involves a midnight dose of 0.5 to $2.0 \mathrm{mg}$ of dexamethasone and measuring the serum cortisol at 0800 hours the next day. Although false negative results occur, patients with Cushing's syndrome should fail to suppress to $100-200 \mathrm{nmol} / \mathrm{L}$ (3.6$7.2 \mu \mathrm{g} / \mathrm{dl}$ ). Suppression to less than $50 \mathrm{nmol} / \mathrm{L}$ or $1.8 \mu \mathrm{g} / \mathrm{dl}$ is highly specific for exclusion of Cushing's syndrome ${ }^{(9,10)}$.

Once Cushing's syndrome is established, the next step is to determine whether the hypercortisolemia is secondary to ACTH excess. Although levels should be repeated for confirmation, corticotropin (ACTH) levels, if low $(5 \mathrm{pg} / \mathrm{ml})$ or undetectable, indicate an ACTH-independent Cushing's syndrome ${ }^{(11)}$. Higher levels indicate some ACTH dependence and the distinction between a pituitary or ectopic source of ACTH secretion then must be made. No single test allows for a clear distinction between pituitary and ectopic sources of excess ACTH. Nevertheless, the combined results of several tests may be used to provide a preponderance of evidence.

The high dose dexamethasone suppression test (HDDST) may be used and involves comparing steroid levels (either plasma cortisol levels or 24-hour urinary levels of 17-hydroxycorticosteriods (OHCS) or UFC) before and after the administration of high dose dexamethasone ( $2 \mathrm{mg}$ of dexamethasone every six hours for 48 hours or a single $8 \mathrm{mg}$ dose of dexamethasone at 2300 hours). Although variations of this test exist and various cut-off values have been assigned, patients with Cushing's disease should show evidence of ACTH suppression (suppression of plasma cortisol by $>50 \%$, UFC by $>90 \%$, 17-OHCS $>64-69 \%$ ), while those with ectopic sources of ACTH do not ${ }^{(12,13)}$.

Metyrapone (administered orally using $750 \mathrm{mg}$ every four hours for six doses), which inhibits the synthesis of cortisol, is also used to distinguish Cushing's disease from ectopic sources of ACTH. While urinary 17-OHCS and 11-deoxycortisol levels and plasma 11-deoxycortisol levels should not rise in patients with ectopic sources of ACTH, rises should be observed in Cushing's disease (rise in urinary $17-\mathrm{OHCS}>70 \%$, or rise in plasma 11-deoxycortisol $>400 \%)^{(14,15)}$.

Corticotropin releasing hormone $(\mathrm{CRH})$ testing is also used to distinguish Cushing's disease from ectopic sources of ACTH secretion. Plasma ACTH and cortisol levels are drawn at times -15, 0, 15, 30, 60, 90, and 120 minutes using a dose of CRH of $1 \mu \mathrm{g} / \mathrm{kg}$ intravenously. In patients with Cushing's disease ACTH and cortisol levels should rise quantitatively more than in those with ectopic ACTH syndromes (peak ACTH $\geq 50 \%$; ACTH $\geq 35 \%$ at 15 or 30 minutes; peak cortisol $\geq 20 \%)^{(16,17)}$. 
Inferior petrosal sinus sampling is an invasive test used to not only confirm a pituitary source of ACTH hypersecretion but also to attempt to localise thetumour within the gland. Catheters are placed bilaterally within the inferior petrosal sinuses and gradients between the central and peripheral plasma ACTH levels are determined with and without $\mathrm{CRH}$ administration ${ }^{(18-22)}$. Central to peripheral ratios greater than 2.0 are considered indicative of Cushing's disease. CRH stimulation $(100 \mu \mathrm{g})$ increases test sensitivity; ratios greater than 3.0 are considered diagnostic of Cushing's disease. Intersinus ratios greater than 1.4 correlate reasonably well with lateralization of the adenoma.

\section{Evaluation of Pituitary Function}

Once the diagnosis of a pituitary adenoma is established, screening tests should be performed to evaluate for signs of pituitary deficiencies. This is particularly important in patients with macroadenomas. The useful screening tests include basal levels of PRL, GH, IGF-1, ACTH, cortisol, LH, FSH, TSH, thyroxine, testosterone, and estradiol. These tests will allow the physician to further establish the pre-treatment endocrine status and the possible need for hormonal replacement.

\section{Imaging Evaluation}

Magnetic resonance imaging (MRI) has emerged as the imaging modality of choice for evaluation of the pituitary. Several points bear mentioning regarding pituitary imaging. When evaluating patients for possible Cushing's disease, the results of MRI should be evaluated with caution. Because clinically significant microadenomas may be too small to be detected using MRI, a normal appearing pituitary gland does not rule out pituitary disease. By the same token, finding an abnormality on MRI does not necessarily confirm the diagnosis of Cushing's disease because a significant portion of the population harbours incidental pituitary tumours. Pituitary tumours have been found in $10 \%$ of the normal population using MRI and in $27 \%$ of persons undergoing autopsy(23,24).

\section{Ophthalmologic Evaluation}

A complete ophthalmologic evaluation is warranted in any patient with visual complaints or imaging evidence of optic nerve compression. Evaluation should include fundoscopy, automated perimetry, and acuity testing. Documentation of visual compromise is not only important for the preoperative evaluation of patients, but also in evaluating the adequacy of therapy.

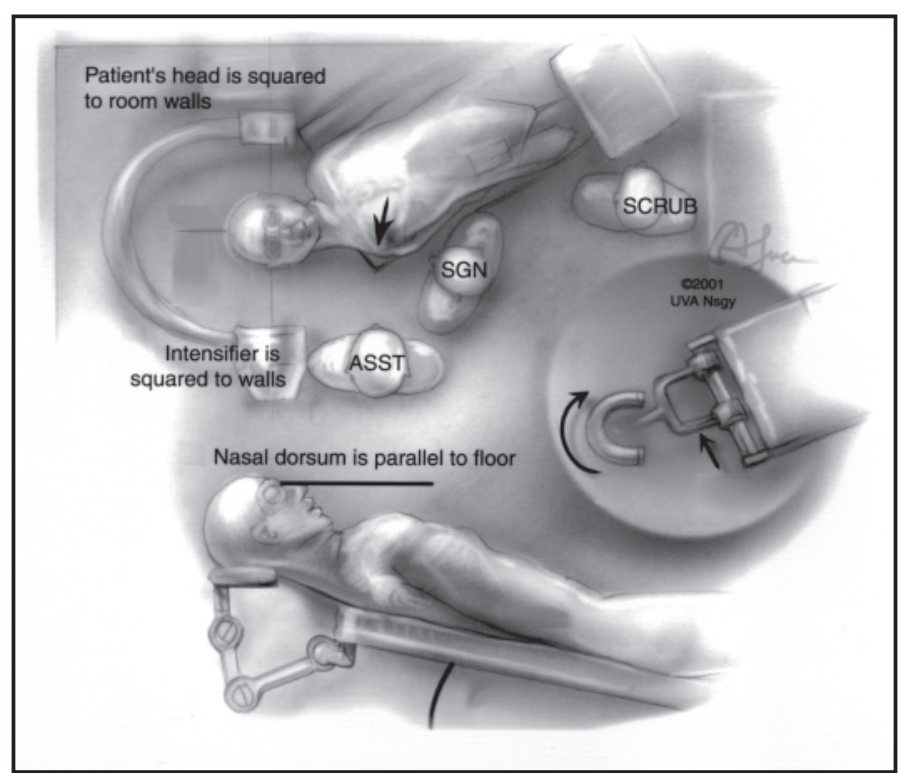

Fig. I Patient positioning and surgical team.

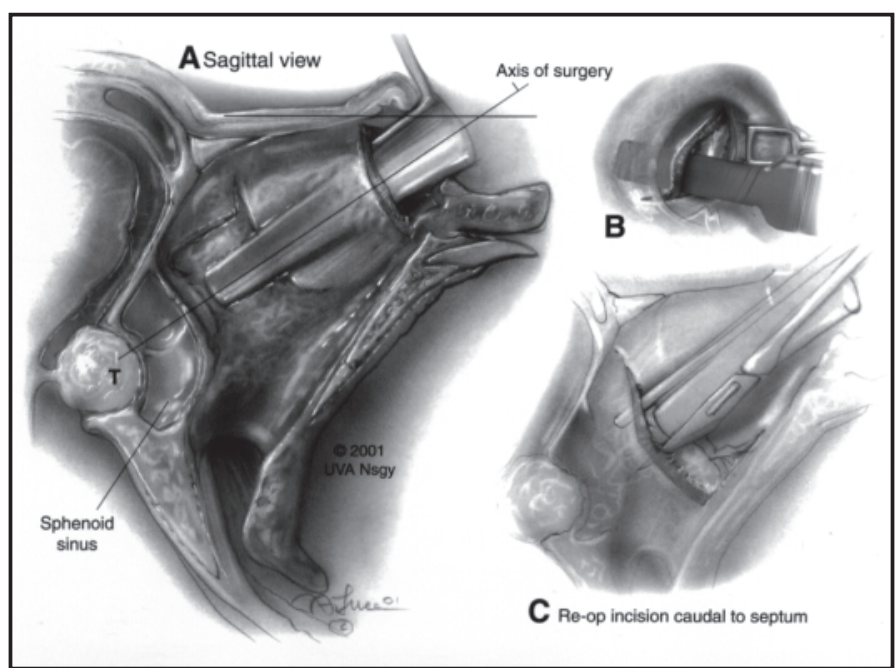

Fig. 2A) Sagittal view of surgical trajectory. B) Endonasal hemitransfixion incision. C) Endonasal septal pushover technique. John A. Jane, Jr.

\section{TRANSSPHENOIDAL SURGERY}

\section{Surgical Approach}

The vast majority of pituitary adenomas may be successfully resected via the transsphenoidal route. Transcranial approaches may be preferred when adenomas extend into the anterior or middle cranial fossa or when the consistency of the tumour is expected to prevent adequate resection of the tumour transsphenoidally.

Patients are placed in a semi-recumbent position with their head placed on a horseshoe headrest (Fig. 1). Although most procedures may be performed endonasally, some pediatric patients with diminutive nostrils and giant macroadenomas are better approached via a sublabial incision. Various endonasal incisions are available to the surgeon depending on the clinical situation (Fig. 2). 
The standard endonasal hemitransfixion incision is increasingly being replaced by septal pushover techniques that allow more direct access to the sphenoid sinus while minimising the risk of septal perforations. Whether performed using endoscopic or microscopic guidance, the goal of surgery is to accomplish a selective adenomectomy that preserves or restores pituitary gland function and decompresses the visual apparatus. Frameless stereotactic image-guidance can aid in the approach to the sella turcica, especially in re-operative transsphenoidal surgery.

\section{Surgical Results \\ Prolactinomas}

Although the first-line therapy for prolactin secreting adenomas is medical, surgery is indicated in those patients who fail to normalise prolactin levels, are intolerant of medications, or whose tumours continue to compress the optic nerves. In our series, prolactin levels are normalised in $56 \%$ of patients harbouring macroadenomas and $87 \%$ of those with microadenomas ${ }^{(1)}$. Recurrence rates after ten years are $13 \%$.

\section{Acromegaly}

Our results indicate that long-term remission may be achieved in up to $67 \%$ of patients ${ }^{(25)}$. Preoperative $\mathrm{GH}$ levels greater than $50 \mu \mathrm{g} / \mathrm{l}$, tumour size, dural invasion, and mixed GH/PRL adenomas significantly predict poor outcome ${ }^{(26,27)}$. Although remission can be achieved in up to $88 \%$ of microadenomas, only $48-65 \%$ of patients with macroadenomas experience remission $^{(1,26-30)}$.

\section{Cushing's Disease}

Transsphenoidal surgery accomplishes remission in 80 to $91 \%$ of patients with microadenomas and $65 \%$ of those with macroadenomas ${ }^{(1,31)}$. Late recurrence after initial remission is particularly prevalent in this disease and can occur in up to $15 \%$ of patients ${ }^{(32,33)}$. In our series, remission can be predicted during the immediate postoperative period if serum cortisol levels taken at 1200 hours on postoperative day one are lower than the preoperative midnight $\operatorname{cortisol}^{(34)}$.

\section{Non-functioning Adenomas}

Visual field deficits are improved in $74-87 \%$ of patients who present with visual compromise ${ }^{(1,35,36)}$. Preoperative pituitary deficiency improves in 13 to $27 \%^{(1,35)}$. Recurrence requiring repeat surgery occurs in $6 \%$ of patients at ten years ${ }^{(1)}$.

\section{CONCLUSION}

Pituitary adenomas may present with classical syndromes of hormonal excess, mass effect, or as incidentally discovered lesions. Appropriate evaluation of pituitary disorders requires careful assessment of the patient's endocrine, visual, and neurological status. Transsphenoidal adenomectomy permits effective treatment for the majority of these tumours.

\section{REFERENCES}

1. Laws ER, Jane JA, Jr. Pituitary tumors - long-term outcomes and expectations. Clin Neurosurg 2001; 48:306-19.

2. Nishizawa S, Ohta S, Yokoyama T, Uemura K. Therapeutic strategy for incidentally found pituitary tumors ( pituitary incidentalomas ). Neurosurgery 1998; 43:1344-8; discussion 8-50.

3. Feldkamp J, Santen R, Harms E, Aulich A, Modder U, Scherbaum WA. Incidentally discovered pituitary lesions: high frequency of macroadenomas and hormone-secreting adenomas — results of a prospective study. Clin Endocrinol (Oxf) 1999; 51:109-13.

4. Donovan LE, Corenblum B. The natural history of the pituitary incidentaloma. Arch Intern Med 1995; 155:181-3.

5. Molitch ME. Pituitary incidentalomas. Endocrinol Metab Clin North Am 1997; 26:725-40.

6. Molitch ME, Russell EJ. The pituitary incidentaloma [see comments]. Ann Intern Med 1990; 112:925-31.

7. Cizza G, Nieman LK, Doppman JL, Passaro MD, Czerwiec FS, Chrousos GP, et al. Factitious Cushing syndrome. J Clin Endocrinol Metab 1996; 81:3573-7.

8. Mengden T, Hubmann P, Muller J, Greminger P, Vetter W. Urinary free cortisol versus 17-hydroxycorticosteroids: a comparative study of their diagnostic value in Cushing s syndrome. Clin Investig 1992; 70:545-8.

9. Wood PJ, Barth JH, Freedman DB, Perry L, Sheridan B. Evidence for the low dose dexamethasone suppression test to screen for Cushing s syndrome - recommendations for a protocol for biochemistry laboratories. Ann Clin Biochem 1997; 34:222-9.

10. Newell-Price J, Trainer P, Perry L, Wass J, Grossman A, Besser M. A single sleeping midnight cortisol has $100 \%$ sensitivity for the diagnosis of Cushing s syndrome. Clin Endocrinol (Oxf) 1995; 43:545-50.

11. Raff H, Findling JW. A new immunoradiometric assay for corticotropin evaluated in normal subjects and patients with Cushing s syndrome. Clin Chem 1989; 35:596-600.

12. Dichek HL, Nieman LK, Oldfield EH, Pass HI, Malley JD, Cutler GB, Jr. A comparison of the standard high dose dexamethasone suppression test and the overnight 8-mg dexamethasone suppression test for the differential diagnosis of adrenocorticotropindependent Cushing s syndrome. J Clin Endocrinol Metab 1994; 78:418-22.

13. Flack MR, Oldfield EH, Cutler GB, Jr., Zweig MH, Malley JD, Chrousos GP, et al. Urine free cortisol in the high-dose dexamethasone suppression test for the differential diagnosis of the Cushing syndrome. Ann Intern Med 1992; 116:211-7.

14. Avgerinos PC, Nieman LK, Oldfield EH, Cutler GB, Jr. A comparison of the overnight and the standard metyrapone test for the differential diagnosis of adrenocorticotrophin-dependent Cushing s syndrome. Clin Endocrinol (Oxf) 1996; 45:483-91.

15. Avgerinos PC, Yanovski JA, Oldfield EH, Nieman LK, Cutler GB, Jr. The metyrapone and dexamethasone suppression tests for the differential diagnosis of the adrenocorticotropin-dependent Cushing syndrome: a comparison. Ann Intern Med 1994; 121:318-27.

16. Nieman LK, Oldfield EH, Wesley R, Chrousos GP, Loriaux DL, Cutler GB, Jr. A simplified morning ovine corticotropin-releasing hormone stimulation test for the differential diagnosis of adrenocorticotropin-dependent Cushing s syndrome. J Clin Endocrinol Metab 1993; 77:1308-12.

17. Kaye TB, Crapo L. The Cushing syndrome: an update on diagnostic tests. Ann Intern Med 1990; 112:434-44. 
18. Oldfield EH, Doppman JL, Nieman LK, Chrousos GP, Miller DL, Katz DA, et al. Petrosal sinus sampling with and without corticotropinreleasing hormone for the differential diagnosis of Cushing $\mathrm{s}$ syndrome. N Engl J Med 1991; 325:897-905.

19. Trainer PJ, Grossman A. The diagnosis and differential diagnosis of Cushing s syndrome. Clin Endocrinol (Oxf) 1991; 34:317-30.

20. Oldfield EH, Girton ME, Doppman JL Absence of intercavernous venous mixing: evidence supporting lateralization of pituitary microadenomas by venous sampling. J Clin Endocrinol Metab 1985; 61:644-7.

21. Oldfield EH, Chrousos GP, Schulte HM, Schaaf M, McKeever PE, Krudy AG, et al. Preoperative lateralization of ACTH-secreting pituitary microadenomas by bilateral and simultaneous inferior petrosal venous sinus sampling. N Engl J Med 1985; 312:100-3.

22. Corrigan DF, Schaaf M, Whaley RA, Czerwinski CL, Earll JM. Selective venous sampling to differentiate ectopic ACTH secretion from pituitary Cushing s syndrome. N Engl J Med 1977; 296:861-2.

23. Hall WA, Luciano MG, Doppman JL, Patronas NJ, Oldfield EH. Pituitary magnetic resonance imaging in normal human volunteers: occult adenomas in the general population. Ann Intern Med 1994; 120:817-20.

24. Burrow GN, Wortzman G, Rewcastle NB, Holgate RC, Kovacs K. Microadenomas of the pituitary and abnormal sellar tomograms in an unselected autopsy series. N Engl J Med 1981; 304:156-8.

25. Laws ER, Vance ML, Thapar K. Pituitary surgery for the management of acromegaly. Horm Res 2000; 53:71-5.

26. Shimon I, Cohen ZR, Ram Z, Hadani M. Transsphenoidal surgery for acromegaly: endocrinological follow-up of 98 patients. Neurosurgery 2001; 48:1239-43; discussion 44-5.

27. Kreutzer J, Vance ML, Lopes MB, Laws ER, Jr. Surgical management of GH-secreting pituitary adenomas: an outcome study using modern remission criteria. J Clin Endocrinol Metab 2001; 86:4072-7.
28. Melmed S, Jackson I, Kleinberg D, Klibanski A. Current treatment guidelines for acromegaly. J Clin Endocrinol Metab 1998; 83:2646-52.

29. Gittoes NJ, Sheppard MC, Johnson AP, Stewart PM Outcome of surgery for acromegaly - the experience of a dedicated pituitary surgeon. QJM 1999; 92:741-5

30. Swearingen B, Barker FG, 2nd, Katznelson L, Biller BM, Grinspoon S, Klibanski A, et al. Long-term mortality after transsphenoidal surgery and adjunctive therapy for acromegaly. J Clin Endocrinol Metab 1998; 83:3419-26.

31. Blevins LS, Christy JH, Khajavi M, Tindall GT. Outcomes of therapy for Cushing s disease due to adrenocorticotropin-secreting pituitary macroadenomas. J Clin Endocrinol Metab 1998; 83:63-7.

32. Yap LB, Turner HE, Adams CB, Wass JA. Undetectable postoperative cortisol does not always predict long-term remission in Cushing $\mathrm{s}$ disease: a single centre audit. Clin Endocrinol (Oxf) 2002; 56:25-31.

33. Chee GH, Mathias DB, James RA, Kendall-Taylor P. Transsphenoidal pituitary surgery in Cushing s disease: can we predict outcome? Clin Endocrinol (Oxf) 2001; 54:617-26.

34. Simmons NE, Alden TD, Thorner MO, Laws ER, Jr. Serum cortisol response to transsphenoidal surgery for Cushing disease. J Neurosurg 2001; 95:1-8.

35. Colao A, Cerbone G, Cappabianca P, Ferone D, Alfieri A, Di Salle F, et al. Effect of surgery and radiotherapy on visual and endocrine function in nonfunctioning pituitary adenomas. J Endocrinol Invest 1998; 21:284-90.

36. Kurosaki M, Ludecke DK, Flitsch J, Saeger W. Surgical treatment of clinically nonsecreting pituitary adenomas in elderly patients. Neurosurgery 2000; 47:843-8; discussion 8-9. 